\title{
Innovations for improving the patient experience in pediatric radiology
}

\author{
Lane F. Donnelly ${ }^{1,2,3}$ (D) \\ Received: 25 March 2020 / Revised: 15 April 2020 / Accepted: 13 May 2020 / Published online: 15 September 2020 \\ (C) Springer-Verlag GmbH Germany, part of Springer Nature 2020
}

In recent times, increasing attention has been given to improving the patient experience in health care. This has also been true in radiology. There has been much discussion about patient satisfaction, patient experience, and patient- and familycentered care - the definition and the differences among each of these areas and what to do to improve them. Paying attention to the non-medical needs of the patient and family is, in a sense, deeply imbedded in the field of pediatrics. Pediatric health care tends to draw those with a devoted dedication to and embrace of the mission of improving the lives of children and their families. It could be argued that children's hospitals have led the way in the area of patient experience, as have pediatric radiology departments for the field of radiology. Still, there is much to be improved.

We are pleased to bring to you this minisymposium focused on the patient experience in pediatric radiology. The minisymposium is composed of articles that touch upon some of the many aspects of what can be done to improve the experience of children and their families in pediatric health care and specifically in pediatric radiology. Topics covered include: using radiology information technology to engage patients, other approaches to engaging patients and families in the pediatric radiology department, the use of patient advocates to improve the experience in pediatric radiology, the role of child life specialists in improving the patient experience, and the approach of the patient experience team at children's hospitals. We hope the topics assembled and the authors' expertise create a set of references that are useful to improving the patient experience.

We thank the assembled authors for their efforts and contributions as well as the Pediatric Radiology editorial staff and the editor of the Americas, Peter Strouse, MD, for the opportunity to create this minisymposium.

\section{Compliance with ethical standards}

Conflicts of interest None

Publisher's note Springer Nature remains neutral with regard to jurisdictional claims in published maps and institutional affiliations.

Lane F. Donnelly

lanefd@stanford.edu

1 Center for Pediatric and Maternal Value, Lucile Packard Children's Hospital - Stanford, Stanford Children's Health,

The Barn, 700 Welch Road, Suite 125 (Room \#104),

Palo Alto, CA 94304, USA

2 Departments of Radiology and Pediatrics, Stanford University School of Medicine, Stanford, CA, USA

3 Stanford Medicine Center for Improvement, Stanford University School of Medicine, Stanford, CA, USA 